\title{
INCREASING RETURNS TO SCALE, PRODUCTIVITY AND ECONOMIC GROWTH - A SPATIAL ANALYSIS OF THE CONTEMPORARY EU ECONOMY
}

This paper is an attempt to explain variations across 261 regions of 27 EU countries in productivity growth for 2000-2013. The study is based on Fingleton's model which analyses the spatial process of productivity growth based on some elements of the theory of New Economic Geography and Endogenous Growth Theory. The applied specification links the productivity growth to the growth of output by means of Verdoorn's law. The model has been tested using the Spatial Panel Durbin Model with Multiple-Level Spatial Fixed Effects. Our findings suggest that increasing returns to scale are present in the EU economy. Moreover, the effect of increasing returns to scale is considerably stronger than has been suggested by both classic and recent research papers. Furthermore, we also find that there are evident spatial clusters of spatial productivity in the EU.

Keywords: increasing returns to scale, productivity growth, Verdoorn's law, spatial panel JEL Classifications: O40, J24, R11, C23

DOI: 10.15611 aoe.2019.1.11

\section{INTRODUCTION}

From the regional perspective there is growing concern about the issue of regional inequality which might be a threat to Europe's social and political cohesion. At the same time, in economic and statistical analyses of the regional development of the European Union, labour productivity modelling has long been recognized as a particularly important research direction. As for example, Freeman (2008) points out, labour productivity constitutes a revealing indicator of several economic factors as it offers a dynamic measure of economic growth, competitiveness, and living standards within an economy. Furthermore, the labour productivity measure is often thought to explain the principal economic foundations that are necessary for economic growth as well as social development. In this paper we attempt to explain variations across NUTS2 regions in productivity growth. Due to the observed presence of the effect of increasing returns to scale, this variation

\footnotetext{
* University of Łódź.
} 
might be an important factor affecting the process of regional convergence within the European Union.

In the past decade, New Economic Geography (NEG) (Fujita et. al., 1999) has been perceived in a renewed way. As a result, the regional analysis of the concentration of economic activity, has placed increasing returns to scale in the mainstream of economics. Although the NEG theory is more a theoretical frame than an applicable formula, it has become more and more popular in applied studies. It has been tested, most notably by means of the cumulative causation modelling and by Verdoorn's Law (Verdoorn, 1949). For example, using regional data and the tools of spatial econometrics, Fingleton and McCombie (1998), Fingleton (2001, 2003, 2006) and Angeriz et al. (2006), amongst others, employed econometric models to test some of the underlying assumptions of the NEG theory.

It is a common belief that a comprehensive spatial analysis should employ some kind of mechanism of differentiating the nature of spatial spillovers. As an example, Paelinck (2013) stated that for each location a region-specific spatial interaction should be adopted since every region has its own level of economic activity. Indeed, just as for the transport flows are different in urban and rural regions, the spillover effects may vary from country to country or even from region to region. Therefore, it seems reasonable to assume that at least regions, group of regions or each country, has its specific time-invariant spatial spillover pattern, which for example, may differ for the pre-2004 EU enlargement member states and for new member states due to, among others, the different initial level of development. Similar differences might occur inside and outside the Schengen Area, inside and outside the Eurozone or along other historically established or culturally justified divides. Thus, the aim of this paper is to capture the spatial variation in regional productivity dynamics within EU NUTS 2 regions.

Considering that labour efficiency is the principal economic factor essential for economic growth and social development, this study aims to provide a multiple analysis of the spatial process of productivity growth within the EU. The empirical model specification makes it possible to formally test the presence and the strength of increasing returns to scale in a comprehensive way. Furthermore, our findings clearly suggest a revision of the quantitative statement of Verdoorn's law in the case of the modern EU economy.

This paper is structured as follows. Section 2 introduces the theoretical background and methodology used in the study. In Section 3 we give 
a description of the variables and data used in the empirical analysis. Empirical results and discussion are presented in Section 4. Finally, Section 5 provides a summary and some concluding remarks.

\section{THE THEORETICAL BACKGROUND AND METHODOLOGY}

The background for the study is the theoretical model developed by Fingleton $(2001,2004)$. This model is based on the NEG theory and Verdoorn's law (see Verdoorn 1949, Kaldor 1957), which links the increase in labour productivity with the increase in production. Verdoorn's law states that in the long run, productivity grows proportionally to the square root of output. This (see Fingleton 2001, 2004) translates to the proportion relation $Q \sim N^{\kappa}$ between output $Q$ and total labour force $N$ with the exponent $\kappa=2$. Thus, a growth in the labour force induces a larger than proportional growth in output due to increasing returns to scale $(\kappa>1)$. As Verdoorn's law embodies the scale effects in the modelling of productivity, this proves to be an important direction in regional growth analysis. By employing some simplifications to the more general NEG theory, Fingleton developed a spatial econometric model and thereby facilitated the testing of some of its hypotheses.

According to, for example, Fingleton (2001), the exponential growth rate of productivity can be modelled by the use of the following specification

$$
p=\alpha_{0}+\rho \mathbf{W} p+\alpha_{1} H+\alpha_{2} G_{0}+\alpha_{3} q+\varepsilon, \quad \varepsilon \sim N\left(0, \sigma^{2}\right) .
$$

where: $p$ is the exponential growth rate of productivity (the amount of final good produced for the level of employment), $\mathbf{W}$ is an $N \times N$ spatial weight matrix for $N$ regions whose elements denote the strength of interregional interaction, with zeros on the main diagonal (cf. Anselin 1988), $H$ is human capital, $G_{0}$ is the initial level of technology, and $q$ is the exponential growth rate of the amount of final good produced. Parameter $\alpha_{3}$ is called Verdoorn's coefficient and, according to the original statement of Verdoorn's law, it is around 0.5 (cf. Bernat 1996, Fingleton and McCombie 1998, Fingleton 2004, Fingleton and López-Bazo 2006), however higher and lower values are also reported in the literature. As the equation $\frac{\kappa-1}{\kappa}=\alpha_{3}$ defines $\kappa$, increasing returns to scale are implied by $0<\alpha_{3}<1$.

In this paper we attempt to capture the spatial variation in regional productivity dynamics, firstly by applying Local Indicators of Spatial 
Autocorrelation (LISA) (cf. Anselin 1988), namely Moran's I statistic. Secondly, we investigate the hypothesis about increasing returns to scale and the spatial relation between the dynamics of labour productivity and the dynamics of output by means of Spatial Panel Durbin Model (SPDM). Namely, Equation (1) is extended to the form of the following SPDM relation:

$$
p=\alpha_{0}+\rho \mathbf{W} p+\pi_{1} q+\pi_{2} \mathbf{W} q+\eta_{1} H+\eta_{2} \mathbf{W} H+\gamma G_{0}+\varepsilon,
$$

where $\alpha_{0}, \rho, \pi_{1}, \pi_{2}, \eta_{1}, \eta_{2}, \gamma$ are model parameters, and $\mathbf{W}$ is spatial weight matrix. Let us note, that variables $\mathrm{p}, \mathrm{q}, \mathrm{H}$ represent panel data. That is $p=p_{t}^{i}, q=p_{t}^{i}, H=H_{t}^{i}$, for all $\mathrm{t}$ and $G_{0}=G_{0}^{i}$ is time-invariant. Additional terms in (2) of spatially lagged exogenous variable are added to account for additional externalities. It should be noted that the legitimacy of including exogenous spatial lags has also been recognized by Fingleton. However, in his earlier papers (Fingleton 2000, 2001) he focused rather on the purely autoregressive specification of the model.

Further specification and expansion of Equation (2) led to the model of form (3) in Section 4, which is a fixed-effects spatial panel Durbin model. We employ a version of the Quasi-Maximum Likelihood (QML) estimation procedure adjusted to accommodate multiple levels of fixed effects. The advantages of using the SDM specification for the investigation of spatial processes are discussed in LeSage and Pace (2009) and Elhorst (2010a).

\section{THE DETERMINANTS AND DATA}

Our study covers 261 regions of 27 EU countries for 2000-2013. All the data used in the study are published by Eurostat ${ }^{1}$, however some missing information was interpolated from the past trends and from data at the NUTS 1 level. This study excludes some French, Portuguese and Spanish regions due to their isolated position, and Croatia because of the lack of reliable data.

Regional labour productivity is described by the quotient of regional production over the number of economically active population $(L)$. Productivity growth $(p)$ for the period 2001-2013 is approximated by the exponential change of regional productivity in these years to the regional productivity in the initial year 2000, i.e. $p=p_{t}^{i}=\ln \left[(G D P / L)_{t}^{i} /(G D P / \mathrm{L})_{2000}^{i}\right]$, where $t=2001, \ldots$, 2013 and $i=1, \ldots, 261$.

\footnotetext{
${ }^{1}$ http://epp.eurostat.ec.europa.eu/portal/page/portal/statistics/search_database - July 2015.
} 
Regional GDP is expressed in millions of euros in constant prices (year 2000), where economically active population is in thousands of people at the age of 15 or over. The map shown in Figure 1 visualizes the distribution of productivity growth in the European regions in 2013 compared to 2000.

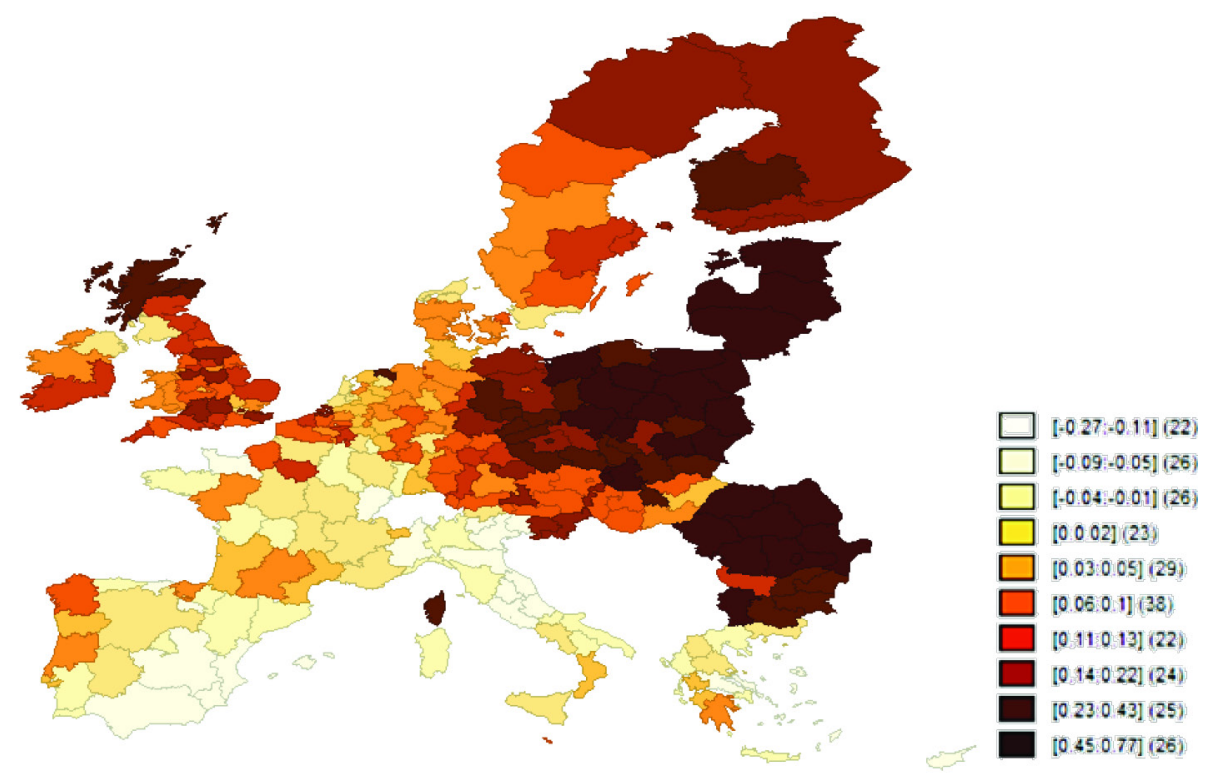

Fig. 1. Exponential change of labour productivity in EU NUTS 2 over the period 20002013 - spatial distribution of $\mathrm{p}_{2013}$

Source: own compilation.

It can be seen in Figure 1 that there is a clear tendency towards the clustering of regions with a similar productivity growth as the regions in light colours, are close to regions in dark colours (positive spatial autocorrelation). The highest growth can be observed for the regions of new EU member states (after EU enlargement in May 2004) with the exception of some regions of Hungary and Bulgaria. Moreover, South-West Oltenia and west and south-east regions in Romania have the highest productivity growth rate for the period 2000-2013-2000. Additionally, within the old EU countries the highest productivity growth is observed for the Highlands and Islands and North Eastern Scottish regions, Groningen in the northern Netherlands, Corsica, west Finland and some regions of Germany: like Bavaria, Brandenburg, Bremen and Sachsen-Anhalt. A similar, however not so evident spatial pattern, was observed for the previous years of the study. 
The exponential change of regional output is approximated by regional production in 2001-2013 to the year 2000: $q=q_{t}^{i}=\ln \left[\left(G D P_{t}^{i} / G D P_{2000}^{i}\right)\right]$, where $t=2001, \ldots, 2013$ and $i=1, \ldots, 261$. Figure 2 presents a visualization of the variable for 2013. We expect a positive impact of the change of regional output on productivity growth with the corresponding coefficient in our model being positive and less than one, which qualitatively accords with Verdoorn's law. Furthermore, according to the theory referred to in Section 2, the effect of change of regional production in neighbouring regions on productivity growth is expected to be negative.

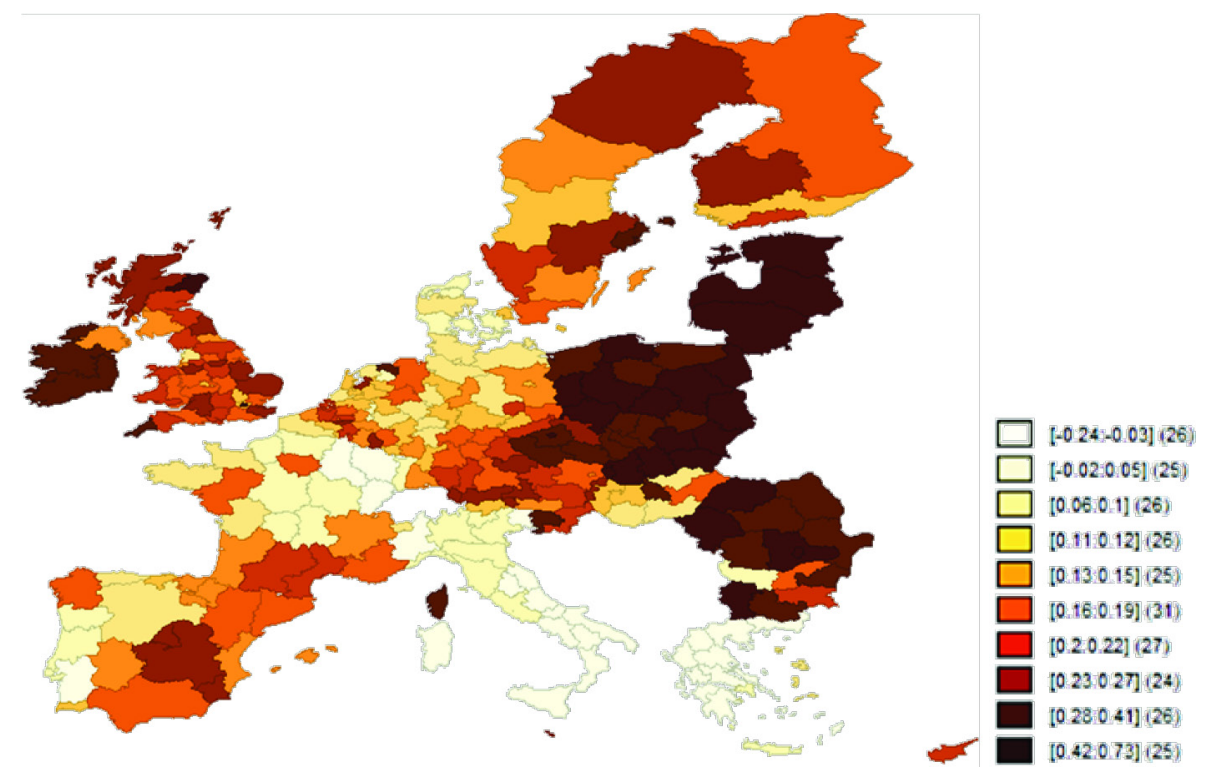

Fig. 2. Exponential change of regional production in EU NUTS 2 over the period 20002013 - spatial distribution of $\mathrm{q}_{2013}$

Source: own compilation.

In the theoretical framework described in Section 2 the initial level of technology $\left(G_{0}\right)$ represents the technological gap between the $i$-th region and the technology leader of the whole economy of the EU. Since the theory assumed is tested through the methodology of a spatial panel model with multiple level fixed effects, the initial level of technology is already incorporated in individual constant terms estimated for each region. 
For the specification of the structure of the spatial effects, we apply a row of standardised spatial weights matrix W $(261 \times 261)$ of three nearest neighbours (cf. Anselin 1988).
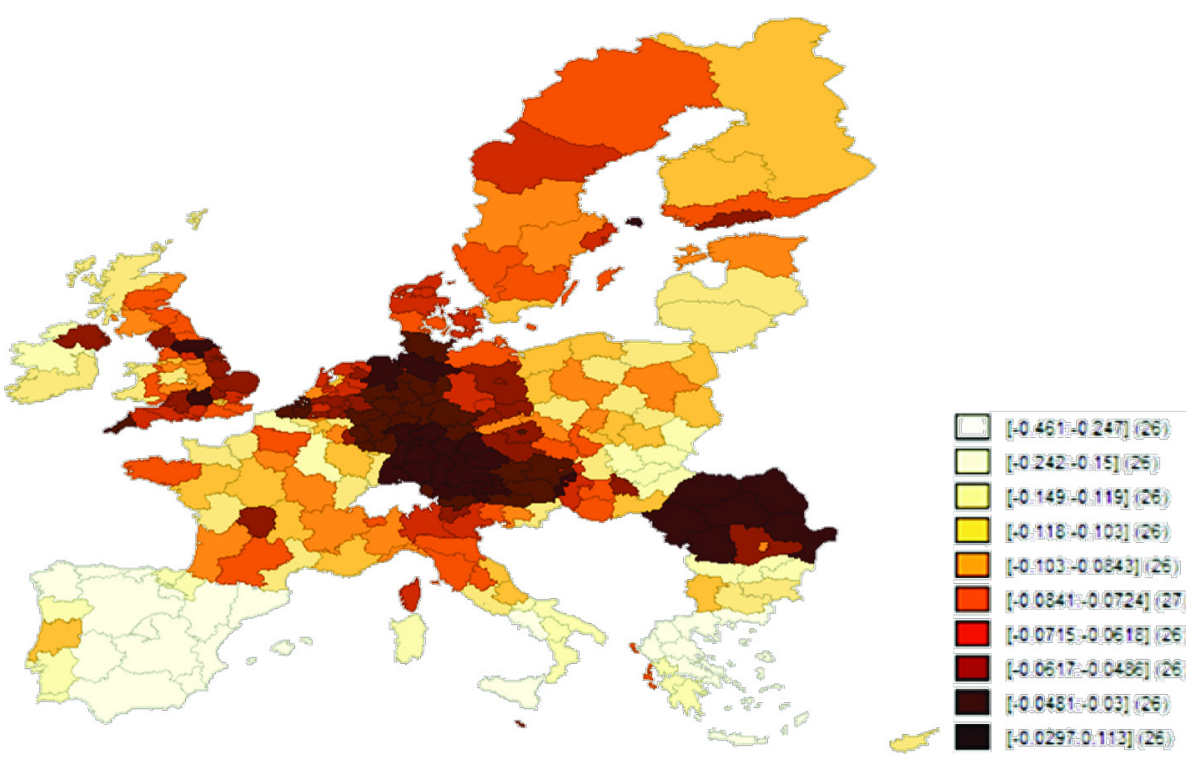

Fig. 3. Natural logarithm of human capital in EU NUTS 2 - spatial distribution of $\mathrm{H}_{2013}$

Source: own compilation.

Human capital is proxied by the human capital in a given region $(H)$ and the human capital in nearby locations $(\mathbf{W} H)$. The former is approximated by the employment in technology and knowledge-intensive sectors $(K)$ as percentage of economically active population $(L): H=H_{t}^{i}=\ln \left[(K / L)_{t}^{i}\right]$, where $t=2001, \ldots, 2013$ and $i=1, \ldots, 261$, and the latter by its spatial lag. We expect a positive impact of human capital on productivity growth as well as positive a spillover effect, confirming the benefits coming from knowledge-intensive neighbours. Figure 3 presents a visualization of the variable $H$ for 2013.

We tested a number of alternative proxies, however we reported just the final ones for which the data available proved to be useful in explaining the productivity growth. Lastly, Table 1 presents some basic statistics of the variables used in this study. 
Table 1

Basic spatiotemporal statistics of the variables used in the model

\begin{tabular}{c|c|c|c|c}
\hline Variable & Mean & Std. dev. & Min & Max \\
\hline$p$ & 0.0901 & 0.1477 & -0.2681 & 0.7683 \\
\hline $\mathbf{W} p$ & 0.0889 & 0.1259 & -0.1488 & 0.6927 \\
\hline$q$ & 0.1348 & 0.1210 & -0.2416 & 0.7501 \\
\hline $\mathbf{W} q$ & 0.1345 & 0.1037 & -0.1262 & 0.5170 \\
\hline$H$ & -0.0925 & 0.0891 & -1.0022 & 0.5633 \\
\hline $\mathbf{W} H$ & -0.0922 & 0.0620 & -0.6862 & 0.2729 \\
\hline
\end{tabular}

Source: own compilation.

\section{EMPIRICAL RESULTS AND DISCUSSION}

The point of departure of the empirical part of the study was the analysis of spatial autocorrelation of the exponential productivity growth rate for each year of the analysis. Figure 4 reports the very strong spatial autocorrelation of productivity growth for the entire period of analysis. This means that there is no random distribution in the change of productivity growth in the EU regions, but regions with high productivity growth tend to have neighbours with comparable high growth, and at the same time regions with low productivity growth also cluster together. Moreover, there is an increasing

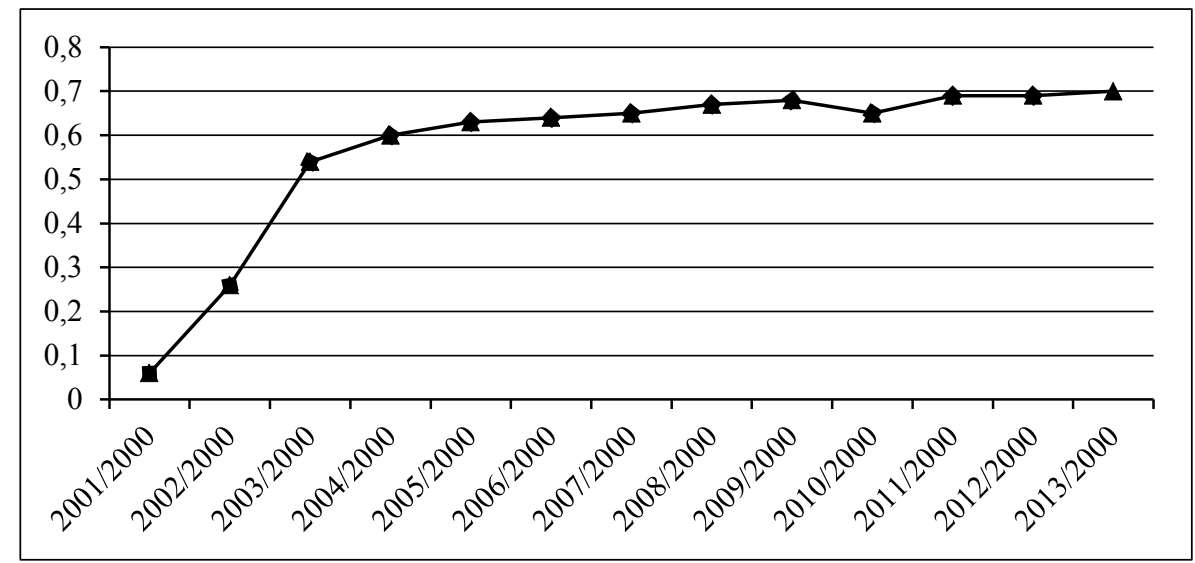

Fig. 4. Moran's I for exponential productivity growth rates for 2001-2013

Source: own compilation. 


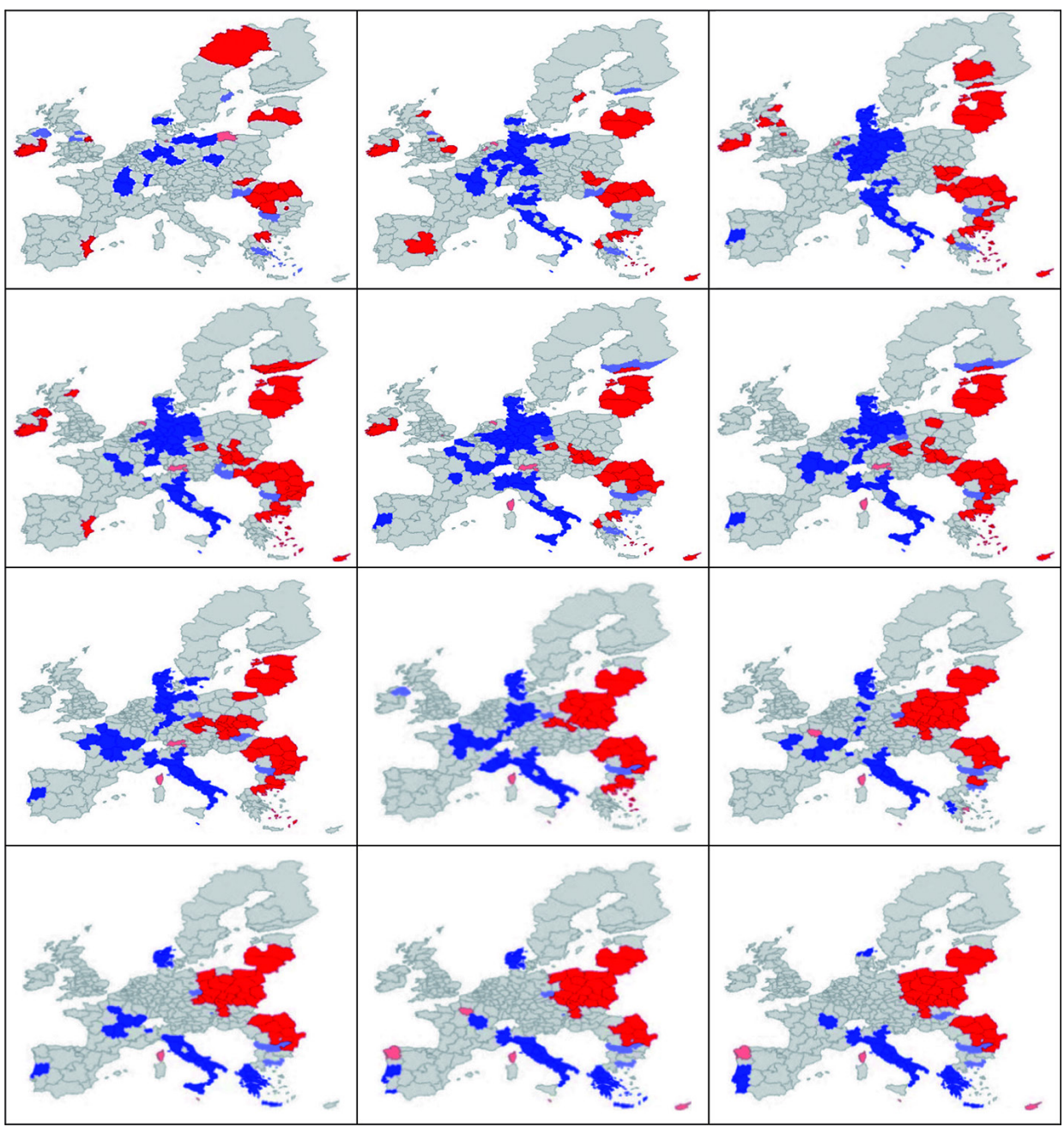

Legend:

$\sqcap$ Not significant $\square$ High-High $\square$ Low-Low $\square$ Low-High $\square$ High-Low

Fig. 5. LISA Cluster Map for productivity growth rate (2002-2013), from left to right, consecutively

Source: own compilation. 


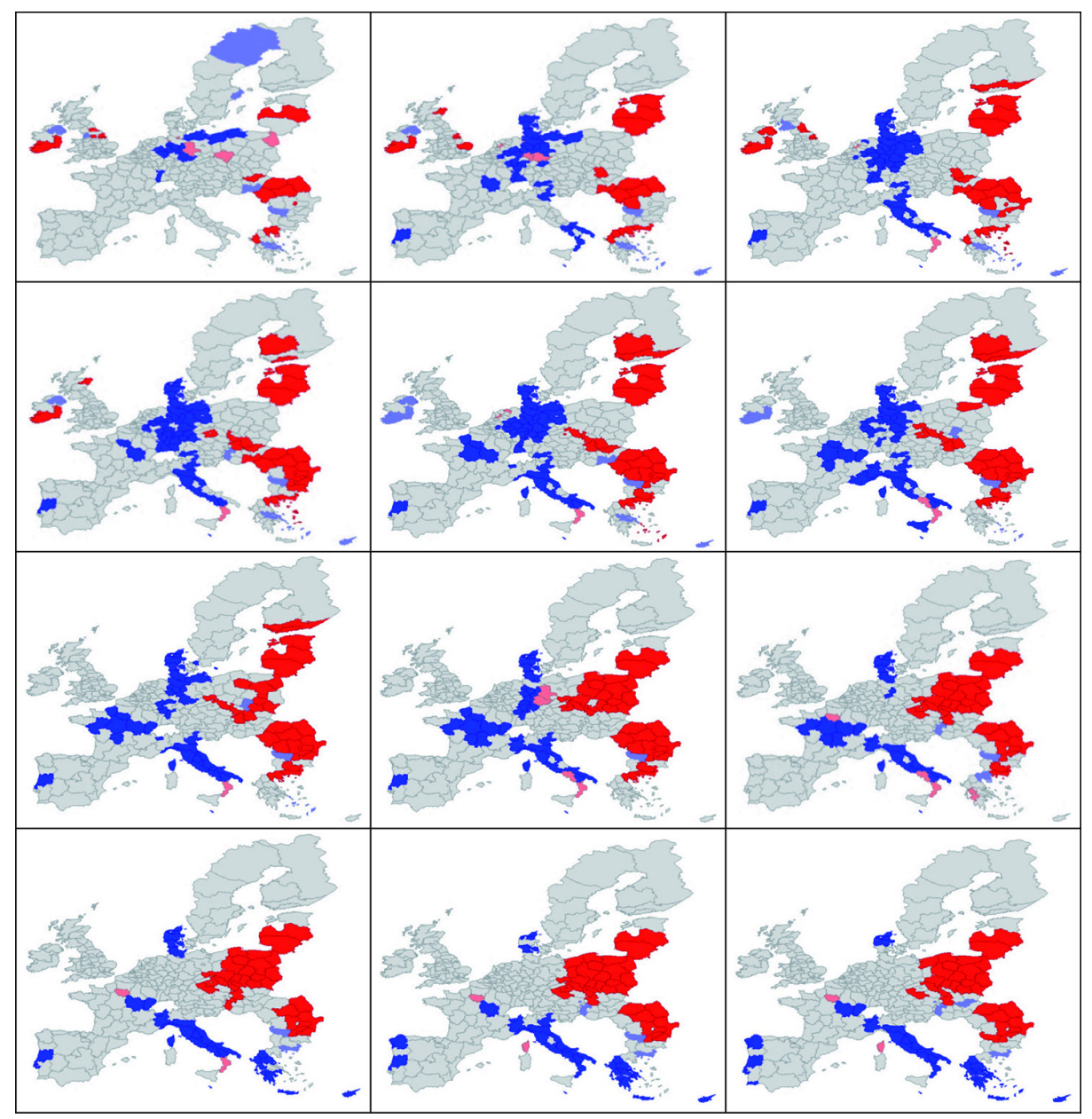

Legend:

$\square$ Not significant High-High

$\square$ Low-Low

$\square$ Low-High $\square$ High-Low

Note: All (except for the year 2001/2000 at 10\% significance level) the reported Moran's I statistics are statistically significant at the level of $1 \%$

Fig. 6. BiLISA Cluster Map for productivity and output growth rates (2002-2013), from left to right, consecutively

Source: own compilation.

trend in the value of Moran's $I$, but at the same time spatial autocorrelation of the exponential change of labour productivity seems to reach long-term stabilisation at the level of $I \approx 0.64$. The reported results were obtained with the 
three nearest neighbours' spatial weights matrix, however for the contiguity spatial weights matrix, the outcomes were not significantly different.

The results described above were confirmed by a LISA cluster analysis (Figure 5) which showed that regions with a high productivity growth rate tend to be surrounded by regions also with high productivity growth rates - a high-high relation, mainly in the eastern part of the EU. Analogously, regions with a low change in productivity tend to have neighbours with a low level of productivity growth - a low-low relation. As visible from the Figure 5, the high-high tendency is becoming clearer with time. A constant in time low-low relation is plainly visible in Italy, Denmark and some French regions.

In order to examine the spatial aspects of the relation between economic performance in the region and productivity growth in the neighbouring areas we conducted a BiLISA analysis (Bivariate LISA, cf. Anselin et al., 2010). As we can see from Figure 6 , bivariate Moran's $I$ statistic is ca. $I \approx 0.5$ throughout the whole period of analysis. ${ }^{2}$ This indicates that the productivity growth in a given region is strongly related to the output growth in neighbouring regions, which justifies using spatially lagged output growth as an explanatory variable. In the eastern part of the EU we can observe a clear cluster of high productivity growth which is accompanied by a high growth rate in the neighbouring regions (high-high relation) in both figures. On the other hand, the low-low cluster is not so much in evidence since for some regions, productivity growth rates vary considerably over the period of the analysis. However, a careful analysis reveals a number of roaming low-low clusters roughly in the centre of the EU map.

In our approach, to discover the numerical value of parameter $\kappa$ we employ fixed-effects panel methodology with multiple levels of fixed effects in order to account for the diversity of regional characteristics. Thus Equation (2) for explaining the exponential rate of productivity growth is further adapted and takes the following form:

$$
p_{t}=\alpha_{0}+\rho \mathbf{W} p_{t}+\pi_{1} q_{t}+\pi_{2} \mathbf{W} q_{t}+\eta_{1} H_{t}+\eta_{2} \mathbf{W} H_{t}+\mu+\varepsilon_{t},
$$

where $\left(\varepsilon_{\tau}\right)_{1 \leq \tau \leq T} \sim N\left(0, \sigma^{2} \mathbf{I}_{T} \otimes \mathbf{I}_{N}\right)$ and $\alpha_{0}, \rho, \pi_{1}, \pi_{2}, \eta_{1}, \eta_{2}, \sigma$ are estimable parameters with $\pi_{1}=(\kappa-1) \kappa^{-1}$ being Verdoorn's coefficient and $\pi_{2}-$ the spatial Verdoorn's coefficient. Furthermore, $\mathbf{W}$ is the $3 \mathrm{nn}$ rowstandardized spatial weight matrix, $p$ represents the exponential labour

\footnotetext{
${ }^{2}$ For the year 2001 and 2002, Moran's I statistics are significantly smaller but still statistically significant.
} 
productivity growth rate, $H$ - human capital and $q$ - the growth rate of production, $\mu$ - spatially differentiated variation term, $t$ - time period (of $T=13$ years 2000 through 2013). Equation (3) incorporates an implied index for region number, say $i$ with $1 \leq i \leq N=261$.

Table 2

Results of the Spatial Panel Durbin Model estimation

\begin{tabular}{|c|c|c|c|c|c|c|c|}
\hline & \multirow[b]{2}{*}{ Corresponding variable } & \multicolumn{6}{|c|}{ Fixed-effect model levels } \\
\hline Parameter & & \multicolumn{2}{|c|}{ Regional } & \multicolumn{2}{|c|}{ Country } & \multicolumn{2}{|c|}{ Old-New } \\
\hline \multicolumn{8}{|c|}{ Coefficient estimates } \\
\hline$\rho$ & $\mathbf{W} p$ & 0.61 & $* * *$ & 0.41 & $* * *$ & 0.60 & $* * *$ \\
\hline$\pi_{1}$ & $q$ & 0.74 & $* * *$ & 0.73 & $* * *$ & 0.76 & $* * *$ \\
\hline$\pi_{2}$ & $\mathbf{W} q$ & -0.45 & $* * *$ & -0.30 & $* * *$ & -0.43 & $* * *$ \\
\hline$\eta_{1}$ & $H$ & 0.08 & $* * *$ & 0.08 & $* * *$ & 0.08 & $* * *$ \\
\hline$\eta_{2}$ & $\mathbf{W} H$ & 0.12 & $* * *$ & 0.09 & $* * *$ & 0.08 & $* * *$ \\
\hline \multicolumn{8}{|c|}{ Marginal effects } \\
\hline \multicolumn{8}{|l|}{ Direct effect } \\
\hline & $q$ & 0.74 & $* * *$ & 0.73 & $* * *$ & 0.77 & $* * *$ \\
\hline & $H$ & 0.12 & $* * *$ & 0.09 & $* * *$ & 0.11 & $* * *$ \\
\hline \multicolumn{8}{|l|}{ Indirect effect } \\
\hline & $q$ & 0.01 & NS & 0.00 & NS & 0.06 & $*$ \\
\hline & $H$ & 0.39 & $* * *$ & 0.19 & $* * *$ & 0.29 & $* * *$ \\
\hline \multicolumn{8}{|l|}{ Total effect } \\
\hline & $q$ & 0.75 & $* * *$ & 0.73 & $* * *$ & 0.83 & $* * *$ \\
\hline & $H$ & 0.51 & $* * *$ & 0.29 & $* * *$ & 0.40 & $* * *$ \\
\hline \multicolumn{8}{|c|}{ Goodness-of-fit } \\
\hline \multirow{2}{*}{$\begin{array}{l}\text { Including fixed } \\
\text { effects }\end{array}$} & $\overline{R^{2}}$ & \multicolumn{2}{|c|}{0.95} & \multicolumn{2}{|c|}{0.85} & \multicolumn{2}{|c|}{0.82} \\
\hline & pseudo $R^{2}$ & \multicolumn{2}{|c|}{0.92} & \multicolumn{2}{|c|}{0.82} & \multicolumn{2}{|c|}{0.74} \\
\hline \multirow{2}{*}{$\begin{array}{l}\text { Excluding fixed } \\
\text { effects }\end{array}$} & Corr $^{2}$ & \multicolumn{2}{|c|}{0.73} & \multicolumn{2}{|c|}{0.56} & \multicolumn{2}{|c|}{0.50} \\
\hline & $\varphi^{2}$ & \multicolumn{2}{|c|}{0.27} & \multicolumn{2}{|c|}{0.44} & \multicolumn{2}{|c|}{0.50} \\
\hline
\end{tabular}

Source: own compilation.

The set of all the spatial units is divided into $G$ disjoint groups $G_{k}$, $1 \leq k \leq G$. The spatially differentiated variation term $\mu=\left(\mu_{i}\right)_{1 \leq i \leq N}$ is a fixedeffect term describing, for each $1 \leq i \leq N$, the departure of the group-timemean of the explained variable $Y=\left(y_{i t}\right)$, namely the average 


$$
\overline{\bar{Y}}_{k(i)}=\frac{1}{\# G_{k(i)}} \sum_{j \in G_{k(i)}} T^{-1} \sum_{i=1}^{T} y_{i t}, \quad \text { when } i \in G_{k(i)},
$$

from the total average value of $Y$, i.e.: $\bar{Y}=(N \cdot T)^{-1} \sum_{i=1}^{N} \sum_{t=1}^{T} y_{i t}$. Naturally, $\sum_{i=1}^{N} \mu_{i}=\sum_{i=1}^{N}\left(\overline{\bar{Y}}_{k(i)}-\bar{Y}\right)=0$.

The spatially differentiated variation term has been investigated through multiple level spatial fixed-effects models at regional level $(G=N)$, and at country level ( $G=26$ ), as well as for the old vs. new member states division $(G=2)$. The empirical results of the estimation of the models are reported in Table 2. It should be also noted that the results of the Hausman specification test suggested the relevance of fixed effects, rather than the random-effects specification.

For all three models all the variables are highly significant (at 0.0001 level), thus have a statistically strong significant impact on the productivity growth in the EU NUTS 2 regions. The spatial autoregressive coefficient $\rho$ is significant, which indicates that productivity growth in neighbouring regions has a significant impact on productivity growth in a given region. Let us note that economic performance $\left(\pi_{1} \approx 0.74\right)$ has a significant and positive effect on productivity growth, which confirms the theoretical assumptions. Therefore we conclude that increasing returns to scale do exist, and faster output growth induces faster productivity growth $(\kappa \approx 3.8)$. Note that Table 2 reports a negative value of $\pi_{2}$, which suggests that an increase in output growth in the neighbouring regions coincides with a decrease in productivity growth in the region. This will be discussed in subsequent paragraphs.

The value discovered for $\pi_{1}$ and $\kappa$ suggest that the effect of increasing returns to scale in the modern EU economy is significantly stronger than what is implied by the classical findings for the theory of Verdoorn (Verdoorn 1949, Kaldor 1966) with $\kappa \approx 2$ in the approximate range 1.6-2.4. However it must be clarified that Verdoorn's original paper concerned a somewhat different economic setting. He analysed the dependence of growth of manufacturing productivity (output per worker) on the growth of manufacturing output (manufacturing value added at constant prices) and found a fairly constant relationship between the rate of growth of labour productivity and output for countries and for industry as a whole. Later, Kaldor $(1957,1966)$ re-examined Vardoorn's original specification 
and additionally investigated a specification with growth of manufacturing employment as the dependant variable (later called the Kaldor specification). The regression coefficients in both Kaldor's specifications were found to be significantly less than one. The finding was interpreted by Kaldor as showing substantial dynamic and static increasing returns to scale. Similarly, Sylos Labini (1983) reports the Verdoorn coefficient for the Italian manufacturing sector to be 0.5, while Casetti and Tanaka (1992) find Verdoorn coefficients of around 0.4 to 0.6 . Even relatively recent papers (McCombie and Thirlwall 1994; Timmer and Szirmai, 2000; Fingleton 2001, $2002,2004)$, which deal with regional data, find $\kappa<2.5$. In Fazio et al. (2013) Verdoorn's law is investigated at both micro and regional level for Italian firms and regions, where the estimates obtained for the coefficient are on average 0.4 or 0.5 , depending on the exact specification.

We then argue that Verdoorn's coefficient $\left(\pi_{1}\right)$ in our specification would be seriously underestimated if we failed to account for the spatial coefficient $\pi_{2}$. Similarly, many of the previous studies in which it is possible to account for spatial interactions, Verdoorn's coefficients might have also been underestimated due to the omitted coefficient $\pi_{2}$.

A number of spatial econometric approaches can be found in the literature of Verdoorn's law, such as Pons-Novel and Viladecans-Marsal (1999), Fingleton and López-Bazo (2006) and Güçlü (2013). Notably, a comprehensive analysis of a number of spatial econometric specifications has been recently conducted in Angeriz et al. (2009). Angeriz et al. consider European NUTS 1 regional data for 1986-2002. They regress total labour productivity on, among other things, output in gross value added in constant prices. Reported estimates of Verdoorn's coefficient in spatial models fall in the range $0.502-0.673$, with clearly higher values in specifications which include lagged output growth.

It has to be noted that the suggested underestimation of the Verdoorn coefficient in a spatial setting may sometimes be also avoided by considering the spatial lag of the error term in econometric specification. This is true especially if Verdoorn's coefficient and the spatial Verdoorn coefficient have opposing signs, and the ratio of their magnitudes is close to the spatial autoregressive coefficient $\rho$. This is consistent with some general facts about spatial econometric model specification, neatly laid out in, e.g. Elhorst (2010b). However, the Durbin model has already been suggested as the preferred specification on economic (theoretical) rather than econometric (technical) grounds. For example, Fingleton and López-Bazo (2006) claim that "choosing the spatial error model in preference to substantive spatial 
dependence in the Verdoorn specification might be erroneous, and mostly caused by misspecification due to the omission of factors determining the rate of technical progress."

Let us note that the sign of the estimates of $\pi_{2}$ reported in Table 2 seems to be in the contradiction to the preliminary analysis of BiLISA (Figure 6). The latter indicates that the productivity growth rate in a given region is positively related to the growth rate in the neighbouring regions. However, the part of variability of $p$ explained by $\mathbf{W} q$ with positive relation is already explained by $q$. The part of the variability of $p$ unexplained by $q$ is explained by the production's growth in the neighbouring regions with the effect being negative. Let us note that similar interactions between variables in multiple regression models were reviewed in Friedman and Wall (2005). Since in our results all the variables, in particular $\mathbf{W} q$, are highly significant, we suggest that failing to include $\mathbf{W} q$ could result in omitted variable heterogeneity and thus lead to biased estimates for $\pi_{1}$ and $\kappa$ itself. Moreover, detailed analysis (which we omit in the present paper) by cosines of angles of relative geometry of $p, q$ and $\mathbf{W} q$ as vectors in $\mathbb{R}^{N \times T}$ space reveals that the bias would be specifically an underestimation of both $\pi_{1}$ and $\kappa$.

One can attempt to generalize the statement about the usefulness of spatially lagged output in specification to a not necessarily spatial setting, in which the units under investigation are subject to (not necessarily spatial) externalities. To give a brief example, one might consider a non-spatial study of a set of branches of manufacturing. Whenever labour productivity or output for the set of those branches, or some explanatory variables are subject to autoregressive relations, then this may result in a form of interbranch externalities. In this case the inclusion of the form $\pi_{2}$ coefficient to some suitable weight matrix might be an essential improvement to the model.

Our findings show that employment in technology and science intensive sectors both in the region and in the neighbouring regions stimulates faster productivity growth, since $\eta_{1}, \eta_{2}$ and the indirect effect for variable $H$ are positive and statistically significant for all three levels of spatially diversified fixed effects. Likewise, the results of all three levels of analysis confirm the thesis of highly increasing returns to scale.

Region-specific time-invariant effects turned out to be significant for the vast majority of the regions, supporting the assumption that there is a significant diversity in the spatial spillovers effects captured by the regionspecific terms, also confirmed by the standard specification test. Similar 
conclusions may be drawn for the country fixed-effects model. The significance of country-specific time-invariant effects suggest that the national-specific effects play an important role in explaining regional productivity growth.

Judging solely by the goodness-of-fit measures, the best model turns out to be the regional model. However the country model still seems to capture a certain important spatial pattern of productivity growth which is otherwise not explained by the determinants of the model alone. Moreover, let us notice the rather unexpected decrease in the strength of the spatial autoregressive effect after imposing common levels of fixed effects for regions within a state. This suggests that some part of the spatial autocorrelation of productivity growth might be attributed to national or country specific factors and further renders the country's fixed-effect specification an interesting alternative to the standard regional fixed-effects approach.

Note that Table 2 presents absolute measures of goodness-of-fit, i.e. adjusted $R$-squared and pseudo $R$-squared for our models, as well as two less standard measures of fit: the Corr $^{2}$ - squared correlation between the dependant variable and the projection as well as $\varphi^{2}-$ the ratio of residual variance to total variance. These two last measures were suitably modified so that they describe the explanatory power of exogenous variables excluding the explanation introduced by fixed effects. The attractiveness of such a modification was suggested in Verbeek (2004) and later Elhorst (2010a), specifically for the Corr $^{2}$ measure. We give the appropriate formulas below.

Let us assume notation $Y_{\text {within }}=Y-\mu-\bar{Y}=\left(y_{i t}-\overline{\bar{Y}}_{k(i)}\right)_{i \leq N, t \leq T}$, c.f. equations (3) and (4), and by analogy $X_{\text {within }}=\left(x_{i t}-\overline{\bar{X}}_{k(i)}\right)_{i \leq N, t \leq T}$, with naturally each $x_{i t}$ being a row vector of observations of explanatory variables. Let $\hat{\beta}, \hat{\rho}$ be coefficient estimates and $\nabla=\mathrm{I}_{T} \otimes\left(\mathrm{I}_{N}-\hat{\rho} \mathbf{W}\right)^{-1}$, then

and

$$
\begin{aligned}
\operatorname{Corr}_{\text {Excl. } \mathrm{FE}}^{2}= & \frac{Y_{\text {within }}^{\mathrm{T}} \nabla Y_{\text {within }}}{\hat{\beta}^{\mathrm{T}} X_{\text {within }}^{\mathrm{T}} \nabla^{2} X_{\text {within }} \hat{\beta} Y_{\text {within }}^{\mathrm{T}} Y_{\text {within }}} \\
& \varphi_{\text {Excl. FE }}^{2}=\left(Y_{\text {within }}-\nabla X_{\text {within }} \hat{\beta}\right)^{\mathrm{T}}\left(Y_{\text {within }}-\nabla X_{\text {within }} \hat{\beta}\right)\left(Y_{\text {within }}^{\mathrm{T}} Y_{\text {within }}\right)^{-1} .
\end{aligned}
$$


The usual way of interpreting econometric model estimates includes inferring about the relations of a change of one variable with a change in another from the explicit values of parameter estimates. However, as LeSage and Pace (2009) suggest that in many circumstances, an alternative way of interpreting the estimates of a spatially autoregressive econometric model might be more appropriate. Namely, one can consider the Fréchet derivative of expectation of the dependant variable $(\mathbb{E} Y)$ treated as a function of the matrix of observations of explanatory variables $(X)$ excluding their spatial lags. This is represented by the matrix of partial derivatives, since the relation between $\mathbb{E} Y$ and $X$ is linear. Then, one is able to compute the socalled direct and indirect effects for each explanatory variable, which in a better way convey the information on the average marginal impact of, respectively, regional and neighbourhood changes in the variable. Estimates for the direct and indirect effects for our models are reported in Table 2.

Let us note that both production growth and relative employment in technology and knowledge-intensive sectors have significant and positive direct effects, therefore they also appear to determine the productivity growth confirming the theoretical assumptions. Moreover, the direct effect of output growth is not significantly different from the value of $\pi_{1}$ for each level of fixed effects. This suggests that accounting for autoregression of productivity growth $(p)$ in the Fréchet derivative $\partial \mathbb{E} p=\left(\mathbf{I}_{N}-\rho \mathbf{W}\right)^{-1}\left(\pi_{1} \mathbf{I}_{N}+\pi_{2} \mathbf{W}\right) \partial q$ (cf. Elhorst 2014), we still obtain the same result on the strength of increasing returns to scale. This all the more lends strong support to the thesis of increasing returns to scale at the high $\kappa \approx 3.94$ rate.

Finally, the indirect effect for $q$ turns out to be insignificant with both $\pi_{1}$ and $\pi_{2}$ being highly significant. This can be regarded as proof of the overall stability of the phenomenon of increasing returns to scale, therefore we suggest that the statistical insignificance of the indirect effect should be interpreted as indicative of the invariability of dependant variable $p$ with respect to the level of $q$ in the neighbouring regions. This implies the stability of the relation between $p$ and $q$ if the latter changes uniformly in neighbouring regions. Let us emphasize that this is not equivalent to the invariability of $p$ with respect to $q$ if the term $\mathbf{W} q$ was not present in the model. The phenomenon might be, in general, referred to as the spatial stability of the relation between the dependant variable and the explanatory variable in a spatial model. In our case, further suggesting the spatial stability of our QML estimates of $\kappa$ - the exponential rate of the increasing returns to scale phenomenon. 
The old vs. new EU member states spatial fixed effects are also significantly supporting the assumption about the relevance of different initial levels of the development of each country. The implications of the empirical results of this model are consistent with the findings for the other two fixed-effects levels, even though the goodness-of-fit measures are slightly weaker than in the first two models.

\section{CONCLUSIONS}

This paper is an attempt to assess the productivity growth in the EU regions for the period 2000-2013. The empirical model is based on Fingleton's model which analyses the spatial process of productivity growth based on some elements of the theory of NEG and Endogenous Growth Theory. Unlike many previous studies (e.g. Fingleton 2000, 2001), we include spatially lagged output growth as an explanatory variable. We suggest that excluding spatially lagged output growth from the empirical form of the model whenever one investigates regional data, constitutes an unnecessary simplification which may lead to biased conclusions. Moreover, we have found the effect of increasing returns to scale in the modern EU economy to be significantly stronger than is implied by the classical findings. Secondly, the LISA analysis presented in this paper proves that there are spatial clusters of labour efficiency in the EU regions. The latter justifies the use of the autoregressive (spatially lagged dependent variable) Durbin specification of econometric model.

Furthermore, it should be clarified that the role of the spatial Verdoorn's coefficient $\pi_{2}$, the use of which we advocate, is essentially adjunctive in the investigation of Verdoorn's law. We suggest that incorporating the $\pi_{2}$ coefficient in a spatial study of the law allows the correct identification of the law's quantitative statement, even if there is no immediate interpretation as to the exact value of $\pi_{2}$ in terms of increasing returns to scale.

We investigated the spatial process of productivity growth within the spatial setting provided by the Spatial Panel Durbin Model with multiple level fixed effects. The model provides evidence of the presence of increasing returns to scale in the process of regional economic growth, which naturally may lead to divergence effects for the EU regions (cf. Kar and Sakthivel, 2008). However, even in the case of divergence of output or productivity, it might still also be possible that their growth rates are subject to conditional convergence. The question whether this is actually the case, could be investigated by means of methodology similar to Olejnik (2008), or 
Kosfeld and Lauridsen (2004). Yet this remains a research problem open for future investigation.

Concluding, we suggest that our findings might constitute an interesting contribution to studies of economic growth and Verdoorn's law. We believe that a more accurate description of the driving forces of productivity growth would play an important role in providing information to put forward better policy recommendations leading to well-informed economic decisions. This allows us to hope that the reinvestigation of the quantitative form of Verdoorn's law may be found interesting by many researchers in the field of economics.

\section{REFERENCES}

Angeriz, A., Mccombie, J., Roberts, M., Productivity, Efficiency And Technological Change In European Union Regional Manufacturing. A Data Envelopment Analysis Approach, "The Manchester School”, 74(4), pp. 500-525, 2006.

Angeriz, A., Mccombie, J., Roberts, M., New Estimates of Returns to Scale and Spatial Spillovers for EU Regional Manufacturing, 1986-2002, "International Regional Science Review", 31(1), pp. 62-87, 2008.

Anselin, L., Spatial Econometrics Methods and Models. Kluwer, Dordrecht, 1988.

Anselin, L., Syabri, I., Smirnov, O., Visualizing Multivariate Spatial Correlation with Dynamically Linked Windows [in:] Anselin, L., Rey, S. (eds.) New Tools for Spatial Data Analysis: Proceedings of the Specialist Meeting. Center for Spatially Integrated Social Science, University of California, Santa Barbara, CA 2002.

Anselin, L., Syabri, I., Kho, Y., GeoDa: An Introduction to Spatial Data Analysis [in:] Fischer, M. M., Getis, A. (eds.), Handbook of Applied Spatial Analysis, pp. 73-89. Springer, Berlin, Heidelberg 2010.

Bernat, G. A., Does Manufacturing Matter. A Spatial Econometric View of Kaldor's Laws, "Journal of Regional Science", 36, pp. 463-477, 1996.

Casetti, E., Tanaka, K., The Spatial Dynamics of Japanese Manufacturing Productivity. An Empirical Analysis by Expanded Verdoorn Equations, "Papers in Regional Science", 71, pp. 1-13, 1992.

Elhorst, J. P., Spatial Panel Data Models [in:] Fischer M. M., Getis A. (eds.), Handbook of Applied Spatial Analysis, pp. 377-407. Springer, Berlin, Heidelberg and New York 2010a.

Elhorst, J. P. Applied spatial econometrics raising the bar, "Spatial Economic Analysis", 5(1), pp. 9-28, 2010 b.

Elhorst, J. P., Spatial Panel Models [in:] Fisher, M. M., Nijkamp, P. (eds.) Handbook of Regional Science, pp. 1637-1653. Springer-Verlag, Berlin, Heidelberg 2014.

Fazio, G., Maltese, E., Piacentino, D., Estimating Verdoorn's law for Italian firms and regions, "Letters in Spatial and Resources Sciences", 6, pp. 45-54.

Fingleton, B., Spatial econometrics, economic geography, dynamics and equilibrium: A third way?, "Environment and Planning", A(32) pp. 1481-1498, 2000. 
Fingleton, B., Equilibrium and economic growth: Spatial econometric models and simulations, "Journal of Regional Science", (41), pp. 117-147, 2001.

Fingleton, B. Some alternative geo-economics for Europe's regions, "Journal of Economic Geography", 4(4), pp. 389-420, 2004.

Fingleton, B., The new economic geography versus urban economics: an evaluation using local wage rates in Great Britain, "Oxford Economic Papers", (58), pp. 501-530, 2006.

Fingleton, B., López-Bazo, E., Empirical growth models with spatial effects, "Papers in Regional Science”, 85(2), pp. 177-198, 2006.

Fingleton, B., Mccombie, J. S. L., Increasing returns and economic growth. Some evidence for manufacturing from the European Union regions, “Oxford Economic Papers”, 50, pp. 89-105, 1998.

Freeman, R., Labour productivity indicators. OECD Statistics Directorate, Division of Structural Economic Statistics, available at: http//www.oecd.org/std/labour-stats/41354425.pdf, accessed on 2 November 2015, 2008.

Friedman, L., Wall, M., Graphical Views of Suppression and Multicollinearity in Multiple Linear Regression, "The American Statistician”, (59)2, pp. 127-136, 2005.

Fujita, M., Krugman, P., Venables, A., The Spatial Economy. Cities, Regions, and International Trade. Cambridge, MA, 1999.

Güçlü, M., Manufacturing and Regional Economic Growth in Turkey. A Spatial Econometric View of Kaldor's Laws, "European Planning Studies”, 21(6), pp. 854-866, 2013.

Kaldor, N., A Model of Economic Growth, "Economic Journal”, 67(268), pp. 591-624, 1957.

Kaldor, N., The Causes of the Slow Rate of Growth of the United Kingdom Economy. Cambridge University Press, Cambridge, UK, 1966.

Kar, S., Sakthivel, S., Regional Divergence in India during the Era of Liberalization. A Sectoral Decomposition [in:] Chopra, K., Rao, C. H. H. (eds.) Growth, Equity, Environment and Population Economic and Sociological Perspectives, pp. 181-197. Sage Publications, New Delhi 2008.

Kosfeld, R., Lauridsen, J., Dynamic spatial modelling of regional convergence processes, "Empirical Economics", 29, pp. 705-722, 2004.

Lesage, J., Pace, K. R., Introduction to Spatial Econometrics. CRC Press Taylor and Francis Group, New York 2009.

Mccombie, J. S. L., Thirlwall, A. P., Economic Growth and the Balance-of-Payments Constraint. Macmillan, London, 1994.

Olejnik, A., Using the spatial autoregressively distributed lag model in assessing the regional convergence of per-capita income in the EU25, "Papers in Regional Science", 87(3), pp. 371-385, 2008.

Paelinck, J. H., Some challenges for spatial econometricians, “Acta Universitatis Lodziensis. Folia Oeconomica. Spatial Econometrics and Regional Economics Analysis”, 292, pp. 11$-20,2013$.

Pons-Novella, J., Viladecans-Marsala, E., Kaldor's Laws and Spatial Dependence. Evidence for the European Regions, "Regional Studies", 33(5), pp. 443-451, 1999. 
Sylos, L. P., Factors Affecting Changes in Productivity, "Journal of Post-Keynesian Economics", 84, pp. 161-179, 1983-84.

Timmer, M. P., Szirmai, A., Productivity Growth in Asian Manufacturing: The Structural Bonus Hypothesis Examined, "Structural Change and Economic Dynamics", 11, pp. 371-92, 2000.

Verbeek, M., A guide to modern econometrics, second edition. Wiley, Hoboken, NJ 2004.

Verdoorn, P. J., Fattori che Regolano lo Sviluppo della Produttività del Lavoro [Labor Productivity Stimulating Factors, own transl.]. "L’Industria”, 1, pp. 3-10, 1949.

Received: June 2016, revised: October 2017 